\title{
School Meals and Food Poverty: Children's Views, Parents' Perspectives and the Role of School
}

\author{
Sónia Goulart Cardoso (iD, Mónica Truninger (iD, Vasco Ramos (iD) and Fábio Rafael Augusto (iD) \\ Institute of Social Sciences, University of Lisbon, Lisboa, Portugal
}

This paper addresses the importance of school meals in balancing food budgets and diets among 45 lowincome families in Portugal. Drawing on interviews with both parents and children (aged 11-15 years) we found that children's views on the quality of school meals affect their willingness to eat at school and heighten parental concerns with health, food and resources. For parents, school meals are crucial to ensure children's dietary variety and balancing tight food budgets. Schools' role in food poverty alleviation is also critically addressed, contributing to current and future sociological studies of children, school meals and food poverty. (C) 2019 John Wiley \& Sons Ltd and National Children's Bureau

Keywords: school meals, low-income families, food poverty.

\section{Introduction}

Research has provided convincing evidence that low-income households are more likely to experience food poverty (e.g. Dowler and 0'Connor, 2012). Among these, families with children are deemed the most vulnerable to food insecurity (e.g. 2019). The effects of food insecurity and insufficient nutrient and calorie intake for children and teenagers are well documented (e.g. Jyoti, Frongillo, and Jones, 2005; Ke and Ford-Jones, 2015). For instance, children under 5 years who experience insufficient food are more likely to experience headaches and colds compared with children whose families are food secure (Alaimo, Olson, Frongillo, and Briefel, 2001). Also, there is a higher prevalence of depressive symptoms and suicide attempts among food-insufficient teenagers (Alaimo, Olson, and Frongillo, 2002). Moreover, these children and teenagers are more likely to have repeated a year at school or dropped out of school, seen a psychologist, been suspended from school or experienced difficulty getting along with others (Alaimo, Olson, and Frongillo, 2001; Baer and others, 2015).

Nevertheless, qualitative studies considering food as a complementary theme to understand how poverty affects families physically, mentally, emotionally and socially remain scarce (e.g. Wills and O'Connell, 2018). Moreover, children's and young people's perspectives on food poverty and how it affects their lives are often absent from food poverty research and literature. Several authors highlight that a thorough assessment of how poverty, inequality and social exclusion impact on food practices could be attained if the children's daily experiences of food poverty were considered (e.g. Lambie-Mumford and Sims, 2018). Qualitative research has shown that children's personal experiences contribute to new conceptions of food practices (for instance, eating more than usual when food is available), and that they actively strive to cope with their circumstances (e.g., Attree, 2006; Cairns, 2018; Connell and others, 2005; Fram and others, 2011; Wall and others, 2015).

Despite the growing interest in children's perspectives, studies focusing on children's food practices at school are still lacking (Wills and others, 2018). Nevertheless, schools stand out 
as a critical context to understand young people eating practices, since children consume a substantial portion of their daily food intake during school time (e.g. Schanzenbach, 2009). Although research about free or reduced-price school meals has shown inconsistent results, some studies have pointed to the benefits of these initiatives for low-income children (e.g. Adolphus, Lawton, and Dye, 2013).

According to Long (1991), free school meals are likely to reduce children's household food expenditure. Additionally, low-income children who are involved in School Breakfast Programs (initiatives that aim at giving breakfast to children before starting their school day, for example, www.fns.usda.gov/sbp/school-breakfast-program-sbp) appear to make healthier choices in meal content and nutrition outcomes (e.g. Bhattacharya, Currie, and Haider, 2006). Nevertheless, while these initiatives may enhance food security among families at risk, they do not necessarily benefit families whose hardships have crossed the food insecurity threshold (Bartfeld and others, 2009).

Although the existing literature suggests that families' income is likely to be a factor underpinning children's eating practices at school, qualitative research on school meals specifically focusing on low-income children and parents' accounts remains largely unexplored (but see 0'Connell and others, 2019a). Our study draws on data from the 'Families and Food in Hard Times' project, granted by the European Research Council (ERC). The project focused on experiences of food poverty among low-income families in three European countries (Portugal, Norway and UK) by exploring children's accounts and parent's perspectives. We focus on the Portuguese qualitative data and give particular attention to the topic of school meals, given it is less widely explored in the international sociological literature on children, low-income families and food poverty. School food was addressed in the qualitative fieldwork (in-depth interviews with parents and children), and several times discussed by parents as an important source for balancing families' tight budgets and appeasing their concerns with children's diets but also as a source of stress.

After offering a brief account of the school meals policy context in Portugal and the research methods employed in the study, the paper addresses children's accounts on school meals and their coping strategies to avoid eating at school. Then, we address parental perspectives on school food. Here, we look at parents' concerns regarding encouraging their children to have a varied and balanced diet and also how children's rejections of eating at school inform a family's food dynamics living under a strict budget. Finally, based on parents' accounts, we offer a perspective on the role of schools in attenuating food poverty for low-income families. We conclude by drawing out the significance of our findings for current and future sociological research on children, school meals and food poverty.

\section{School meals policies in Portugal}

Truninger, Horta, and Teixeira (2015) carried out a documentary analysis of the Portuguese school meals' regulatory framework since the 1970s. They concluded that concerns with children's nutrition gained more importance after the 1974 Revolution (transition from the authoritarian State to a democratic government), becoming a priority in recent years. From the end of the 1990s until the mid-2000s, school meal policies were oriented towards tackling excess weight and obesity (Truninger and others, 2013). Nowadays, beyond concerns with hygiene, nutrition, health and food safety norms, school meal policies are paying attention to seasonality, regional food cultures, commensality, environmental issues (e.g. fish should come from sustainable sources), reducing meat consumption and increasing plantbased diets, all encompassed by the general promotion of the Mediterranean Diet in schools (Cardoso and others, 2018; Pereira and Cunha, 2017; Truninger and others, 2013). 
School meal services are co-managed by the schools, the local state authorities or the central government, depending on the level of education. The local authorities (municipality or parish councils) manage the nurseries' and primary's school meals, whereas the Ministry of Education centralises and oversees the management of secondary school meals. In the school year 2019/2020, this will change under the administrative devolution regulatory framework that will allow municipalities (if they wish so) to take charge of secondary school's meals. In primary schools, parents' associations can also manage school meals, but this is seldom.

Every school-aged child is entitled to eat school lunch every weekday. Prices are determined by law every year and subsidised by the Ministry of Education and local authorities. According to the legislation in force (cf. Despacho 8452-A/2015, Diário da República, 31 July 2015), the price of a school meal is $1.46 €$ (if bought in advance or with a $0.30 €$ penalty if paid on the day). The Services of School Social Action (Serviços de Ação Social Escolar, SASE) are organised in three brackets of support (A, B and C) depending on the family's income. Students in brackets A and B have 100 per cent and 50 per cent of school food expenses covered by public funds respectively. The remaining students (bracket C) pay the full price for their meal. Some schools use their financial resources to provide a food supplement during the morning/afternoon break. These supplements consist of bread (with butter, cheese or ham), sometimes accompanied by milk and fruit (usually provided by free fruit schemes such as the EU school fruit regime).

According to Lima (2018) all schools provide a standard menu which consists of: (i) a fresh vegetable soup (with potatoes, legumes or beans); (ii) one meat, fish/seafood with pasta, rice or potatoes and legumes (optional) on alternate days; (iii) one brown bread; (iv) one plate of vegetable salad (raw or cooked); (v) one dessert composed of raw seasonal fruit together with cooked or baked fruit without sugar or pudding, jelly, ice cream, yoghurt (twice a month maximum); (vi) water is the only drink available. The menu varies every week, and it is announced to the school community. Salt reduction is greatly promoted, and the use of aromatic herbs is encouraged as a salt replacement. Regarding food preparation, some schools have cooking facilities and staff to serve school meals (in-house catering services) while others rely on meals prepared by external catering companies. Some of these prepare meals at school kitchens (if cooking facilities are available), and others use a central kitchen and later distribute the meals to schools. As explained by Truninger and Sousa (2018), taste and quality issues are at stake when different food catering systems are implemented. Children often prefer food that is prepared in the school kitchen premises (since it resembles home cooked food) over food that is prepared outside schools, has travelled some distance accommodated in temperature regulated containers and then served at school, or has been transported, then reheated in school before being served.

\section{Research methods}

As mentioned earlier, this paper draws on the research project 'Families and Food in Hard Times' that analysed experiences and implications of food poverty in low-income families in three European countries. The research followed a mixed methods approach, combining interviews with direct observation and visual methods. In Portugal, 45 low-income families living in an urban and suburban area of Lisbon (30 families), and a rural area in Sintra (15 families) were recruited and interviewed. Most families were recruited through local schools, with a few being contacted via NGOs and food banks. While the selection criteria were having at least one child between 11 and 15 years of age and on a low income, a strong effort was made to obtain a diverse sample (in terms of age, education, ethnicity, employment status, household income number of children, marital state, family structure). All the families participated voluntarily and written informed consent was obtained. 
Research followed two stages. In the first stage, children (11-15 years old) and their parents/caregivers were interviewed separately (in-depth semi-structured interviews). These interviews took place in a location of the families' choice, for instance, their house, our university, a local café, a local charity or school. The interviews with parents and children lasted between 30 minutes to $3 \mathrm{~h}$ and were recorded with participants' consent. In the second stage, 12 of these families were selected for a tour of their kitchen and a follow-up interview, which lasted about half an hour. Likewise, kitchen tours and follow-up interviews were recorded, with consent being obtained beforehand. On this second stage, we also provided children with a camera and asked them to take photos of their meals over 2 weeks. After that period, we revisited families and conducted a follow-up interviews with parents and a photo elicitation interview with the children, that is, children were invited to comment on the photos they had taken in a narrative way.

All interviews were transcribed. Transcriptions and other materials were anonymised, following data protection procedures. Thus, all our interviewees' names used in this paper are aliases.

To analyse the empirical data, we adopted a case study approach. Case summaries were produced for each family (parent and child) addressing the main themes of the project (e.g. eating habits during the day and the weekend, food budget management, main expenses and income sources, domestic division of foodwork, social participation and eating out, food strategies to cope with tight food budgets). Case comparisons were made, looking for commonalities and differences across each family. Since our sample encompasses school-aged children, school meals were a recurrent topic discussed in the interviews with both children and parents, thus, given its importance to families and its scientific relevance, this paper focuses on this issue.

This paper comprises the findings of the Portuguese fieldwork regarding the views of children on school meals, parents' perspectives on school food for minimising economic constraints and the role of schools in food poverty alleviation. It draws on the qualitative analysis of empirical material gathered during the interviews with children and adults conducted in both phases but excludes the visual methods data (analysis of the photos) due to space restrictions. For our analysis, we considered a final sample of 44 families (44 children and 44 parents/caregivers, 88 interviews in total), as in one family the child was not attending school at the time of interview due to irregular immigration paperwork. Thus, 15 children attended a school in a rural area at the time of the interviews, while the other 29 children were enrolled in schools in urban/suburban areas.

In the next section, we present our findings while quoting some interviewees. Information regarding their status (parents: mother/father; children = girl/boy), age and area of residence (urban/rural) are added next to their pseudonyms.

\section{Findings}

\section{Children's perspectives of food at school}

The majority of the children in our sample reported eating at school very often (4-5 days per week). Only 18 children reported not eating at school often. Thirty-three children were in bracket A and received free school meals. Seven children were in bracket B and paid $0.73 €$ per meal. Four families were not entitled to a free or discounted meal paying the full price (1.46€) when children ate at school. The selected schools located in more deprived neighbourhoods also provided to children in brackets A and B a free food supplement during the morning/afternoon break, often bread with butter, ham or cheese and some milk or water. 
Based on children's accounts, we identified two main reasons for children not eating at school often: their position in the social security brackets and their views on the quality of school meals. First, children who are not entitled to free or discounted meals reported eating at school less often than children with free or discounted lunches. Entitled children ate mainly at school, whereas others ate mainly at home, which added to the food budget of their parents. Second, regarding the quality of school meals, while some children liked them, most declared that they preferred home cooked food, a finding that was confirmed by other studies of school meals in the country (Truninger and Sousa, 2018; Truninger and others, 2013). Only two children complained about the quantity of food served.

Teresa (girl, 15, rural): They give us a little amount, indeed (...) the teachers have a full plate almost like a mountain and us, flat (...). [Whereas the teachers have] a full plate of soup, full main dish.

Marta (girl, 12, urban): When the food is good and when we can eat a bit, we want seconds afterwards... and the staff won't let us have it because there is not enough food for everyone.

Children often questioned the quality of food. The main complaints revolved around food taste, smell and appearance. Soup and fish were the foods that were usually criticised, corroborating the results from other studies in the country (Truninger and Sousa, 2018). Salt was referred to as an important part of a 'tasty' and 'caring' meal.

Gonçalo (boy, 13, rural): At school, they aren't concerned [about food] [...] for example, they don't season the food. The salad isn't seasoned either (...).

Deonilde (girl, 15, urban): It's awful, the school food is awful, with no salt, they make food... Imagine mashed potatoes, they make mashed potatoes with fish and it looks like porridge, because first the fish is full of scales and they don't remove that at all and the mashed potatoes is like soup on a plate, so, sometimes we eat it with a spoon because you can't eat it with a fork.

Comparing with home cooked meals, Carla (girl, 12, urban) claimed that 'food at home is tastier, because it's warm and has more flavour and our mother never forgets anything, neither salt nor olive oil'. In a way, Carla associated food at home with love and commitment towards meal preparation. Carolina (girl, 10, urban) also preferred food prepared at home: 'Because it's made by my parents, with love and care and also it's food I'm more used to and like more (...)'.

\section{Children's strategies to avoid eating at school}

Our results showed that children adopted a variety of strategies to avoid eating food they disliked at the school canteen. While some children bought something at the school bar or in a café nearby the school, others had lunch at home, brought their food from home or skipped lunch entirely.

For instance, Catarina (girl, 14, urban) eats two portions of soup when she does not like the main dish. Zé (boy, 15, rural) usually eats at the school cafeteria. However, when the main course is fish, he buys food at the school bar (e.g. bread with chorizo). Constança (girl, 12, rural) eats at the school bar when she does not like what is on the menu. Likewise, Miguel (boy, 14, urban) condemns food quality at school, especially fish: 'The fish is green (ish). It has no salt. And the potatoes have no flavour'. Thus, whenever there is fish on the menu, he buys a sandwich or pastry with juice in a coffee shop near the school. Although 
Miguel's parents do not scold him for not having fish at school and give him money to lunch outside the school, they are concerned about his diet and warn him to avoid eating 'junk food'. Miguel: (...) I always tell my parents that I can't eat the food at school, I can only eat the meat dishes. Then they say: 'so when it is meat you have lunch there, when it's fish, you don't eat. You eat that... Father will give you money or mother will give you money and you go buy [something to eat]'.

Miguel's father (52, urban): He and many others, don't like the food at school, it's not just him. Many, many kids don't like it, they go outside, there's a grocery store, they sell bread with chorizo for $1 €$, bread with chorizo and the juice or bottle of water, he doesn't like to eat at school much.

Children not appreciating school meals is not a surprising finding per se; other studies have reached similar conclusions, not only in Portugal but also in the UK (Pike and Kelly, 2014). What is interesting to stress is the economic effort that low-income parents make to ensure children have food in their stomachs and do not skip lunch, even if they go out of school. Also, Miguel's father seems to 'normalise' the practice of skipping lunch at school and eating outside for as little as €1. As this is what other kids do, so Miguel does it too. Group belonging, social integration and not being excluded from what is 'normal' practice supplants having a nutritiously balanced, albeit not very appetising, meal at school.

There were other strategies of resistance to school meals. As an example, Luana (girl, 11, urban) and Sofia (girl, 15, urban) sometimes bring a packed lunch from home when they do not like the menu at school, despite being entitled to free school meals. Although Samara (girl, 14, urban) has free school meals, she always lunches at home. She lives nearby the school, walks home and eats on her own while the mother is working. Her mother cooks in advance and leaves the dish ready to be reheated. Pedro (boy, 11, urban) also refuses to eat in the school canteen and has lunch at home every day since he moved to this new school a year ago. Allegedly, Pedro has seen cockroaches in the school canteen and 'became disgusted to eat there'. Both Samara and Pedro live in an urban area near their school which facilitates their mobility. We noticed that opting to eat at home even when entitled to free school meals is more frequent for children who live within walking distance from school and in urban areas. Most children in rural areas live far from school and do not have frequent public transport, having to eat at school more often than children from urban areas.

Four children admitted skipping lunch (partially or in full) when they disliked the school food. For instance, Gonçalo (boy, 13, rural) buys something in the school bar when he has some spare money or skips the lunch altogether when he is short of money and does not like the dish on offer (often a fish dish). When he arrives home, his mother realises whether he had lunch or not, depending on how hungry he is.

Regarding the children who declared liking school meals, only three praised school food. For example, Bartolomeu (boy, 14, urban) thinks the food at school is better than at home. His family food is mostly dependent on the help of the local food bank or a non-governmental association designed to help end both hunger and food waste (Re-food). Bartolomeu: The school's food is better (...) because we rarely have the school food at home. Like, mashed potatoes with hamburger. But not that hamburger in a bun, and those things. And sometimes when it's the end of the year, they make chips with meat and things like that.

\section{Parents' perspectives on school meals}

Similar to the children, parents also raise concerns about the quality of school meals. The majority of parents talk to their children about school meals and are aware of children's 
complaints. Despite this, all parents consider that free school meals are crucial in alleviating their family food budget. Even those who pay the full fare ascertain that the low price of school meals makes them cheaper than homemade meals. Thus, some parents actively persuade their children to eat at school. For example, Manuela (mother, 48, rural) encourages her son to eat at school even when he only has classes after lunch. Clara (mother, 40, urban) refers to how important free school meals are in preventing that her children suffer food insecurity.

Clara [tearful]: (...) That's why I prefer it, when they have lunch at school, even when they like the food a little less... I ask them to have lunch, because I don't know if I'll have dinner... (...) I ask them to eat, because sometimes I don't know what will come... and sometimes they have to eat toast for dinner and... bread. Drink chocolate milk and such things... I mean... and I'm more relaxed if they've had a meal already.

For several families, school meals are also crucial to ensure that children have a varied diet. Some parents acknowledge that their children are only able to eat fish at school, instead of at home, given its high price in supermarkets/markets. Leoni's (mother, 37, urban) case highlights this concern with the mother being adamant to her children about the need for eating at school. Leoni's family is dependent on help to obtain food (they get support from Re-food and the food bank). A free meal at school ensures a nutritiously sound hot meal a day for her children. However, her son dislikes fish and has only soup and fruit for lunch. Leoni told us that her son was not accustomed to eating fish, which makes fish 'strange' to his taste buds, given he is not familiar with the taste of fish.

Leoni: (...) there are many things my son sometimes doesn't like and doesn't eat. For example, not because he doesn't like it, because he has never eaten much so he didn't learn to like it. Often times it's fish.

Interviewer: He won't eat fish?

Leoni: He doesn't want it, because he says he doesn't like it, because he feels a sensation in his head, because we rarely buy fish at home, they were never used to eating fish, and they often don't think why kids don't like it. All 4 are like that, but it's not [because of a picky behaviour]. It's because they rarely eat fish, my children, very rarely.

Eduarda (mother, 46, rural) considers fish very important to maintain a good diet. As she is not able to buy it often due to its steep cost, she instructs her children not to skip fish at school:

Eduarda: I try, but sometimes I know it's not... Sometimes fish is lacking, but they need fish, but sometimes we don't have it because it's too expensive and we don't buy it.

Interviewer: And your children, do you think they have a good diet?

Eduarda: Because at school they try to eat fish, I say "You eat fish at school", because at home... and sometimes they eat fish at school.

The rotation of school meals' menus (meat one day, fish on the following) can also play a role in 'training' children's palates, as illustrated by Sara's account. She claims that her son extended the range of foods he eats by eating at school, and now eats dishes at school that he would often reject at home. 
Sara: He continues to reject the fish, he hates fish, he's put in his head that his friends only eat meat (...) I explained that one needs to eat fish. In school he has no choice but to eat the fish (...) he is used to it already because we eventually train the palate (mother, 36, rural).

In the case of António (boy, 14, urban), his friends and teachers influenced him to diversify his diet. António was not used to eating a variety of food in early childhood. For that reason, he has a visceral repulsion to many foods, as his mother explained: 'He's eating more... and if he eats other things, he vomits right away'. After eating pork sandwiches in a restaurant near the school encouraged by friends and teachers, António continued to eat that food and now 'That's what he wants to eat'.

\section{School food and family dynamics: taboos, concerns and stress}

For some families, concerns about school meals and their quality influence family dynamics. For instance, for Susana (mother, 30, urban) the poor quality of school meals represents a taboo that the family does not discuss. Food at school is essential to complement the lack of food at home, and thus Susana is afraid of 'knowing for sure' that the food is terrible.

Susana: (...) I normally don't ask what my daughter eats (...) Sometimes I hear bad things about the school meals and so I am not going to ask so I don't need to think that she eats badly at school... (laughing).

For Henrique (father, 45, urban) and Aida (mother, 49, rural), the school meals are also a constant concern. These parents mention that their children are very particular with food and do not have lunch at school when they dislike the menu. When children arrive home, they realise whether they had lunch or not, depending on how hungry they are.

Henrique: “I know that in the school sometimes, you see... doesn't... doesn't eat. There are some days that she eats, but I know when she doesn't because... I ask her 'what did you had for lunch?' and she says 'it was this or that', and did you eat? 'yes', and I know that is a lie because she didn't like it, you see? (...) When she arrives home and eats something, I know she didn't eat properly at school.

Aida: (...) I think he goes hungry so the say the least ... If... if, for instance, my parents give him $5 €$ or when I have I give him $5 € \ldots$ and he can eat at the school bar ... some sandwich, a juice ... (...) When he doesn't have money, I think he doesn't even eat.

Finally, Isabel (mother, 30, urban) showed us the importance of school meals for children with special dietary needs but also the additional stress that these meals could represent for parents. Her daughter has a chronic disease, and the school provides a special dietary meal, although not in conformity with Isabel's daughter's tastes.

Isabel: While the others might eat fries and everything, she doesn't eat [...] And she says she doesn't like the soup, because the soup often has no salt, has no flavour, she says the school food has no flavour.

\section{Eating during school holidays: a hard period for low-income families}

Given the importance of school meals, holidays are a challenging time for low-income families. On the one hand, parents have to allocate more money for food. For instance, one mother referred that although her children are not entitled to free school meals, she spends 
twice as much on food during holidays, making this a hard period to manage. On the other hand, holidays entail increasing concern about meals' schedules, conciliation with parents working hours and alterations on the type of food provided. For instance, because they are at home, there are more occasions for consumption and children eat other types of foods, such as snacks, fruits or 'chilly foods' (such as jellies or ice cream).

Lina (mother, 32, urban): Summer is very difficult, because it's like this, in the summer they want fresh things [...] Instead of taking $2 \mathrm{~kg}$ of meat, I take $1 \mathrm{~kg}$ of fish. To cook or grill, really more to grill, which is fresher. It ends up being less. For example, a meal that was good for two days, with $2 \mathrm{~kg}$ of meat, is only good for one. Then it becomes more complicated. They want chillier things. They, for example, they eat more jelly... they like to eat more ice cream, made at home... (...) summer holidays... It's chaos! It's like saying, I don't know what to do! Because it's lunch, dinner/lunch, dinner/snacks... fruit, because they eat a lot of fruit. I'm always asking for fruit [at the food bank or Refood]... which is the freshest thing I can have possibility of ...

Some parents develop particular coping strategies to deal with the summer holidays. During the 3-month summer holidays, Isabel (mother, 30, urban) reaches her maximum of money spent on food, around $300 €$. Children always eat at home and Isabel has to cook three meals: lunch, afternoon snack and dinner. Then, she sacrifices nightly snacks: 'During the night, they're used to eating a glass of milk or eating bread and butter before going to bed [...] And there are times they can't do that'. Other parents rely on informal support and send their children off to relatives to have their meals.

Marco: No, he either stays some days with his godmother, stay some days with his great grandmother, spend some days with my brother, some days with his godmother, spend some days with me here. When he's not here, I'd organize things better (father, 52, urban).

Tânia: I'm worried more because my daughter is at home more time, but I also worry less, because she also goes to my parents' house. And the meals there are also good and normal. So, it is both a concern and it is not (mother, 48, rural).

Elvira (mother, 47, rural) is the only exception since for her it is easier to manage meals during school holidays because she knows what his son likes to eat and can prepare meals adjusted to his preferences. Her son only eats a minimal range of foods, dislikes unfamiliar foods and does not eat any starchy food (e.g., rice) if mixed with other ingredients.

\section{The role of schools in alleviating food poverty}

During the fieldwork with children and parents, it became clear that schools have an important role beyond the provision of meals for low-income families. When analysing parents' accounts we encountered several initiatives promoted by the school and their staff in order to alleviate different dimensions of food poverty. Parents mentioned various school staff as having an important role in their lives: schools' social services, teachers, kitchen staff and even children's schoolfriends and classmates. Despite not always being aware of each other's role, they ended up complementing, and interconnecting with, one another.

For example, sometimes schools make use of their autonomy to bypass central government social services' decisions that they consider inadequate. An example is when they use 
their school resources to cover the cost of meals for children of low-income families who are struggling because of bureaucratic delays in receiving social security benefits or in changing their Tax Revenue status.

Moreover, school staff also contributes to attenuating families' food insecurity situation. Truninger and Sousa (2018) showed that primary school cooks adjust their way of cooking to ensure children ate fish, for example, by removing bones and shredding fish to be quickly eaten by children. Our findings also show similar initiatives; for example, one of the interviewed mothers works in a school canteen and shares a strategy she uses to encourage students to eat soup.

Luz: (...) when we serve, we try to be friendly, and sometimes instead of serving like this (she gestures to demonstrate a full bowl) we serve like this (she gestures to indicate a bowl with little soup). Because sometimes the amount is frightening. An almost full bowl is not the same as a smaller bowl... And they end up eating something (mother, 38, rural).

More importantly, parents recognise this 'caring role' and praise the sensibility of kitchen staff to adjust to children's tastes. Random actions of the school staff (very often against the schools' internal regulations) lessen parents' worries about the quality and quantity of school food.

For example, some staff members use their own money to buy seasoning to add to fish dishes, because they consider the taste inadequate due to the way fish is cooked by the catering companies. The latter have to comply with nutritional regulations that recommend the reduction in salt and employing other ways of seasoning dishes (e.g. aromatic herbs). However, parents' and children's accounts often refer to salt as an important ingredient for a 'tastier meal'. The last national food survey (IAN-AF, 2016) drew attention to the fact that the Portuguese population consumed high quantities of salt (e.g. added to soups) and recommended a substantial reduction in salt consumption. The government has strongly promoted policies for salt reduction in the food industry and in school meals since the survey's findings were launched, given the increasing health risks associated with excess salt consumption.

Against school rules, at times the staff offer additional snacks to children or distribute unsold items from the school bar at the end of the day. One mother, Liliana, (42, urban) praised the fact that the school staff felt some empathy towards children from low-income families:

Liliana: (...) snacks sometimes are a little weak because it's bread and butter or a dessert... [...] I'm going to tell you a secret. . .

Interviewer: Yes, yes, of course

Liliana: “(...) The staff in the bar are very sweet to the kids, because they themselves perhaps suffer some problems, that's the way it is, that's life! Because wages are small, we know this, right? Of the staff! And sometimes they know the kids, some live here in the area and know the kids face hardships. And they themselves when there is leftover cake or something like that, some small snack... instead of the bread, they give that to the children. Which is great, they're great! Because they're not taking anything, they're taking nothing! [...]

Also, there are parents who personally ask school staff to fortify their children with snacks. 
Clara: If I ask dinner ladies to fortify their snacks, they go with them to the kitchen... and sometimes give them something more. They give them soup at the afternoon and then... I don't worry as much (mother, 40, urban).

Some teachers encourage pupils to support those who might be experiencing food poverty by volunteering in food banks. Also, they hold 'food-raising' events to build food baskets in class for Christmas or use their own money to cover difficult situations. For instance, Leoni's (mother, 37, urban) daughter's teachers collected money to give the family a birthday cake. This situation was praised by Leoni who would not be able to provide for the birthday cake otherwise. 0'Connell and others (2019b) have highlighted the need to approach food poverty as a multidimensional phenomenon that should consider the social dimensions of food, for instance, the ability to provide for special occasions (e.g., Christmas, birthdays). Our findings suggest that teachers could represent a source of informal support on the social dimensions of food poverty.

In addition, teachers have an essential role in introducing new foods to students. Some students stated that their food practices have changed and that they eat more vegetables because of schools' and teachers' influence.

Finally, children establish strong social and solidarity bonds with their schoolmates, and food sharing is a common practice, with children from families that are better off buying food or lending money to children whose families are worse off.

Isabel (mother, 30, urban): Often a classmate pays them a pastry or something else, then they divide among themselves.

Lina (mother, 32, urban): (...) I went to school and know perfectly how it is. A bag of chips is good for the whole class. I mean, it's always been that way (...).

\section{Conclusion}

This paper analysed 45 in-depth interviews with low-income families, focusing on children's views and their parents' perspectives on school meals. Analysis indicated that the majority of children are eligible for free school meals. Our results are consistent with those obtained by Fox and Condon (2012), showing that children eligible for free and reduced priced meals eat more at school than those who are not eligible for free school meals. Nevertheless, we also found that children's views on the quality of the school meals determined the extent to which they ate school lunches. The majority of children raised complaints about the quality of the school food (e.g. taste, appearance and smell) and resorted to several coping strategies to avoid eating food that they disliked (such as fish). They would buy food in the school bar (usually sandwiches or pastry) or outside the school (mainly fast food); share food with colleagues; eat at home (especially when living within walking distance from school); bring a packed lunch from home or skip lunch altogether.

In some cases, children's coping strategies ended up overloading the family's food budget, since parents were forced to give some money for their children to buy food (inside or outside the school) or to cook extra food for them to eat at home or prepare a lunch box. Also, these issues raise parental health concerns about the quality of food eaten by their children, since they often go for fast food, or end up eating smaller portions or not eating at all during the school day.

Similar to children, parents also raise concerns about the quality of school meals. However, unlike their children, parents focus more on the consequences of the lack of quality in food intake for their families as a whole. When children refuse to eat at school or are not 
eligible for free school meals, parents' concerns about the family food budget and children's health and well-being grow.

In addition, parents highlight the importance of eating at school to alleviate pressure on the family budget and to provide more variety ('doesn't eat fish at home, but at least he can eat it at school'). The findings reflect previous research (Gill and Sharma, 2004) which highlight parents' difficulties in providing healthy meals during school holiday periods. However, our study also revealed other parental concerns during children's school holidays in Portugal where rates of full-time maternal employment are high in comparison with other European countries: food management is (even) more problematic during this period since all children's meals are made at home, children demand specific foods and parents have to juggle their busy work-family schedules. Consequently, many parents have to adopt coping strategies such as cutting on their meals or drawing on informal support (e.g. food given by family members).

In summary, children's accounts focused primarily on the quality of the school meals, whereas parents' perspectives encompassed other concerns beyond the quality of the meal. These included issues that have an impact on family dynamics and children's overall eating habits and dietary intake (e.g., school food as a complement to the diet at home, offering more variety, health and nutrition than the family lighter meals).

Finally, our research showed that parents greatly value the informal support of schools in attenuating the constraints of low-income families. Members of the school's staff intervene, and schools use their funds to support struggling families in many ways. Teachers use their influence to raise children's awareness about poverty and food insecurity and also provide for special occasions. They also motivate children to try new food when eating at school. The bar and cafeteria staff often assume the role of caregivers, giving children extra food or buying seasoning to flavour foods with their own money. Children also support one another and share food brought from home (e.g. lunch boxes) or bought outside the school.

Thus, schools and their staff emerged not only as important in determining the quantity and quality of food but also in contributing to the alleviation of the social dimensions of food poverty that involve exclusion from customary food and eating activities (e.g. by providing for special occasions, social participation with colleagues).

In sum, our research adds to the evidence that school meals contribute to shaping children's food practices and serve simultaneously to provide support for families who are experiencing food poverty. On the one hand, school meals are recognised by some parents to contribute to providing a varied diet for their children and alleviating pressure on the family food budget. On the other hand, despite more generous entitlement than in some countries such as the UK, not all low-income children are eligible for free or reduced-price meals, and even eligible children sometimes refuse to eat at school. Moreover, children's food consumption at school also relates to their perceptions of food quality, influencing parents' food budgets, changing families' dynamics and raising parents' concerns.

While a lack of options during holidays amplifies low-income families' constraints, the 'solution' of providing school meals in holidays should be interpreted with caution since it can only offer an immediate solution that does not structurally solve families' poverty (Husz, 2018). As highlighted by O'Connell, Brannen and Knight (2018 (p. 1), offering school meals on holidays 'goes nowhere near far enough and cannot tackle the underlying factors that lead to the food poverty of children and their families'. It is important to note that the informal network that emerges in school can be perceived as a quick fix of temporary family economic struggles. However, it is also an amplification signal of something more severe and structural underneath: the State is failing and not complying dutifully with its obligations. 
Our focus on children's and parents' accounts has proven to be informative of the specific challenges that low-income families face regarding children food consumption at school. Studying the school context also contributed to broadening our understanding of how food relates to family dynamics and household income. Since schools and their staff have emerged as crucial sources of informal support, further work could lend additional critical insight into the role of schools and meal provisioning for food poverty alleviation. It would be important to analyse the implications for children, families and schools of positioning the school as a source of food support, at times even replacing State action, and its capacity to intervene in protecting citizens from food poverty.

\section{Acknowledgments}

This work was supported by the European Research Council under grant 337977; and the Portuguese Science and Technology under grant SFRH/BPD/116221/2016. The paper uses data from the 'Families and Food in Hard Times' research project (www.foodinhartimes.com). The international research team comprises Rebecca 0'Connell, Julia Brannen, Abigail Knight, Laura Hamilton, Charlie Owen and Antonia Simon (UK); Silje Skuland and Anine Frykholm (Norway) and Monica Truninger, Karin Wall, Vasco Ramos, Sónia G. Cardoso, Fábio R. Augusto and Manuel Abrantes (Portugal). We are also grateful for the valuable time kindly given by the children and parents who agreed to participate in the study. This research reflects only the authors' views and the European Union is not liable for any use that may be made of the information contained therein.

Fábio Rafael Augusto would like to acknowledge the funding received for his $\mathrm{PhD}$ (grant reference SFRH/BD/130072/2017) from the Portuguese Foundation for Science and Technology (FCT), co-funded by the European Social Fund (FSE) and national funds of the Portuguese Ministry of Science, Technology and Higher Education (MCTES) through the Human Capital Operational Programme (POCH).

\section{References}

Adolphus K, Lawton CL, Dye L. 2013. The effects of breakfast on behavior and academic performance in children and adolescents. Frontiers in Human Neuroscience 7: 1-28. https://doi.org/10.3389/fn hum.2013.00425.

Alaimo K, Olson CM, Frongillo EA, Briefel RR. 2001. Food insufficiency, family income, and health in US preschool and school-aged children. American Journal of Public Health 91: 781-786.

Alaimo K, Olson CM, Frongillo EA. 2001. Food insufficiency and American school-aged children's cognitive, academic, and psychosocial development. Pediatrics 108(1): 44-53.

Alaimo K, Olson CM, Frongillo EA. 2002. Family food insufficiency, but not low family income, is positively associated with dysthymia and suicide symptoms in adolescents. Journal of Nutrition 132: 719-725.

Attree P. 2006. The social costs of child poverty: a systematic review of the qualitative evidence. Children \& Society 20: 54-66.

Baer TE, Scherer EA, Fleegler EW, Hassan A. 2015. Food insecurity and the burden of a health-related social problems in an urban youth population. Journal of Adolescence Health 57: 601-607.

Bartfeld J, Kim M, Ryu JH, Ahn H-M. 2009. The school breakfast program: participation and impacts. Contractor and Cooperator Report no. 54, July. USDA: Washington, DC. Electronic report from the Economic Research Service.

Bhattacharya J, Currie J, Haider SJ. 2006. Breakfast of champions? Journal of Human Resources 41(3): 445-466. https://doi.org/10.3368/jhr.xli.3.445.

Cairns K. 2018. Relational foodwork: young people and food insecurity. Children \& Society 32: 174184. 
Cardoso SG, Augusto FR, Nunes NC, Graça J. 2018. Public support for vegetarian meals in public canteens: a preliminary study. In Changing Societies: Legacies and Challenges, Vol. 3. The diverse worlds of sustainability. Delicado A, Domingos N de Sousa L (eds.). Imprensa de Ciências Sociais: Lisbon; 297-315.

Connell C, Lofton K, Yadrick K, Rehner T. 2005. Children's experiences of food insecurity can assist in understanding its effect on their well-being. The Journal of Nutrition 135(7): 1683-1690.

Dowler E, O'Connor D. 2012. Rights-based approaches to addressing food poverty and food insecurity in Ireland and UK. Social Science \& Medicine 74: 44-51.

Fox MK, Condon EM. 2012. School Nutrition Dietary Assessment Study - IV. Available at http:// www.mathematica-mpr.com/publications/PDFs/nutrition/sndaiv_findings.pdf [Accessed 28 December 2018].

Fram MS, Frongillo EA, Burke MP, Jones SJ, Williams RC, Burke MP. 2011. Children are aware of food insecurity and take responsibility for managing food resources. Journal of Nutrition 141: 1114-1119.

Gill 0, Sharma N. 2004. Food Poverty in School Holidays. Available at http://www.barnardos.org.uk/f oodpovertyreportv3.qxd.pdf [Accessed 15 December 2018].

Husz I. 2018. "You would eat it if you were hungry". Local perceptions and interpretations of child food poverty. Children \& Society 32(3): 233-243. https://doi.org/10.1111/chso.12274.

Jyoti DF, Frongillo EA, Jones SJ. 2005. Food insecurity affects school children's academic performance, weight gain, and social skills. The Journal of Nutrition 135(12): 2831-2839. https://doi.org/10.1093/ jn/135.12.2831.

Ke J, Ford-Jones E. 2015. Food insecurity and hunger: A review of the effects on children's health and behaviour. Paediatrics Child Health 20(2): 89-91.

Lambie-Mumford H, Sims L. 2018. Feeding hungry children: the growth of charitable breakfast clubs and holiday hunger projects in the UK. Children \& Society 32(3): 244-254. https://doi.org/10.1111/ chso.12272.

Lima R. 2018. Orientações sobre ementas e refeitórios escolares. Ministério da Educação: Direç̧ão-Geral da Educação (DGE): Lisbon.

Long SK. 1991. Do the school nutrition programs supplement household food expenditures? The Journal of Human Resources 26(4): 654-678. https://doi.org/10.2307/145979.

0'Connell R, Knight A, Brannen J. 2019a. Living Hand to Mouth: Children and Food in Low Income Families. Child Poverty Action Group: London.

0'Connell R, Owen C, Padley M, Simon A, Brannen J. 2019b. Which types of family are at risk of food poverty in the UK? A relative deprivation approach. Social Policy and Society 18(1): 1-18.

0'Connell R, Brannen J, Knight A. 2018. Child food poverty requires radical long term solutions. BMJ 362: k3608. https://doi.org/10.1136/bmj.k3608.

Pereira F, Cunha P (Coords.). 2017. Referencial de Educação para a Saúde. Ministério da Educação Direção Geral da Educação; Direção-Geral da Saúde: Lisboa.

Pike J, Kelly P. 2014. The Moral Geographies of Children, Young People and Food Beyond Jamie's School Dinners, 1st edn. Palgrave Macmillan: London, UK.

Schanzenbach DW. 2009. Do school lunches contribute to childhood obesity? Journal of Human Resources 44(3): 684-709.

Truninger M, Sousa R. 2018. School meal reform and feeding ordering in Portugal: conventions and controversies. In Feeding Children Inside and Outside the Home. Harman V, Cappellini B Faircloth C (eds.). Routledge: London and New York, NY; 42-62.

Truninger M, Horta A, Cardoso SG, Augusto FR, Teixeira J, Fontes A. 2019. Alimentação em Tempos de Crise: Consumo e Segurança Alimentar nas Famílias Portuguesas. Imprensa de Ciências Sociais: Lisboa.

Truninger M, Teixeira J, Horta A, da Silva V, Alexandre S. 2013. Schools' heath education in Portugal. A case study on children's relations with school meals. Educação, Sociedade \&t Culturas 38: 117-133.

Truninger M, Horta A, Teixeira J. 2015. School meals in Portugal: governing children's food practices. Revista de Humanidades 25: 31-55.

Wall K, Almeida AND, Vieira MM, Cunha V, Rodrigues L, Coelho F, Leitão M, Atalaia S. 2015. Impactos da Crise nas Crianças Portuguesas: Indicadores, Políticas, Representações. Imprensa de Ciências Sociais: Lisboa. 
Wills WJ, 0'Connell R. 2018. Children's and young people's food practices in contexts of poverty and inequality. Children and Society 32: 169-173. https://doi.org/10.1111/chso.12278.

Wills WJ, Danesi G, Kapetanaki AB, Hamilton LK. 2018. The socio-economic boundaries shaping young people's lunchtime food practices on a school day. Children \& Society 32(3): 195-206. https://doi. org/10.1111/chso.12261.

Correspondence to: Sónia Goulart Cardoso, Instituto de Ciências Sociais da Universidade de Lisboa, Av. Professor Aníbal de Bettencourt, 9, 1600-189 Lisboa, Portugal, Tel.: + 351 968487435; Fax: 217940 274. E-mail: sonia.goulart.cardoso@gmail.com

Accepted for publication 4 May 2019 